\title{
Carotid Vessel Wall Imaging on CTA
}

\author{
(D) H. Baradaran and (D) A. Gupta
}

\section{ABSTRACT}

SUMMARY: Vessel wall imaging has been increasingly used to characterize plaque beyond luminal narrowing to identify patients who may be at the highest risk of cerebrovascular ischemia. Although detailed plaque information can be obtained from many imaging modalities, CTA is particularly appealing for carotid plaque imaging due to its relatively low cost, wide availability, operator independence, and ability to discern high-risk features. The present Review Article describes the current understanding of plaque characteristics on CTA by describing commonly encountered plaque features, including calcified and soft plaque, surface irregularities, neovascularization, and inflammation. The goal of this Review Article was to provide a more robust understanding of clinically relevant plaque features detectable on routine CTA of the carotid arteries.

ABBREVIATIONS: IPH = intraplaque hemorrhage; LRNC = lipid-rich necrotic core

$\mathbf{R}$ ecent advances in vessel wall imaging have spurred a paradigm shift in the evaluation of carotid plaque. Despite decades of using a degree of luminal stenosis as the primary determinant of treatment for patients with carotid artery stenosis, there has been a recent trend toward adopting advanced imaging techniques to provide a more complete plaque evaluation for more accurate risk assessment. Much of the literature of vessel wall imaging has centered on MR imaging because of its impressive contrast resolution and high sensitivity for identifying high-risk plaque features. ${ }^{1,2}$ In addition to MR imaging, contrast-enhanced sonography is also a powerful tool for evaluating carotid plaque vulnerability. ${ }^{3-5}$ CTA is often overlooked as a method for providing detailed evaluation of plaque characteristics, and it has certain benefits in terms of accessibility and ease of use in clinical workflow not present with multisequence MR imaging characterization of carotid plaque. Although CTA does not have the same prospective evidence as MR imaging and ultrasound for predicting future cerebrovascular disease,

Received September 5, 2019; accepted after revision December 17.

From the Department of Radiology (H.B.), University of Utah, Salt Lake City, Utah; and Department of Radiology (A.G.), Weill Cornell Medicine, New York, New York.

Hediyeh Baradaran is supported by a grant from the Association of University Radiologists-GE Radiology Research Academic Fellowship Award. Ajay Gupta is supported, in part, by National Institutes of Health grants R01HL144541 and R21HL145427.

Please address correspondence to Hediyeh Baradaran, MD, Department of Radiology, University of Utah, 30N 1900 E, Room \#1A71, Salt Lake City, UT 84135; e-mail: hediyeh.baradaran@hsc.utah.edu

- Indicates open access to non-subscribers at www.ajnr.org

http://dx.doi.org/10.3174/ajnr.A6403
CTA does provide valuable information regarding plaque characteristics that should not be ignored.

CTA of the head and neck is a commonly acquired examination to evaluate vessel patency in the setting of cerebrovascular ischemia, especially in the work-up of acute ischemic infarction. In addition to providing accurate information regarding the degree of luminal stenosis, CTA examinations can also provide rich detail regarding plaque morphology and features, given their superb spatial resolution. While identifying thrombosis and the degree of stenosis on CTA is necessary in selecting patients for intervention, other plaque features evident on CTA are also valuable in determining the risk of stroke or TIA and in aiding management decisions. In this review, we will describe technical considerations when performing CTA and then provide detailed descriptions of individual plaque characteristics that can be evaluated on CTA. For each plaque feature, we will summarize the existing literature, associating each feature with stroke risk. We will also include practical considerations and comparisons with other imaging modalities.

\section{Clinical Background}

Extracranial atherosclerosis is an important contributor to stroke, accounting for $15 \%-20 \%$ of all ischemic strokes. ${ }^{6,7}$ With improvement in medical management for treating patients with carotid artery stenosis, the annual risk of stroke has decreased in asymptomatic patients to $\sim 1 \%$, ${ }^{8}$ which has made the need to appropriately risk-stratify patients even more critical. Traditionally, imaging risk assessment has been based on the degree of arterial narrowing as measured by the NASCET criteria, which have been used as the basis for randomized 


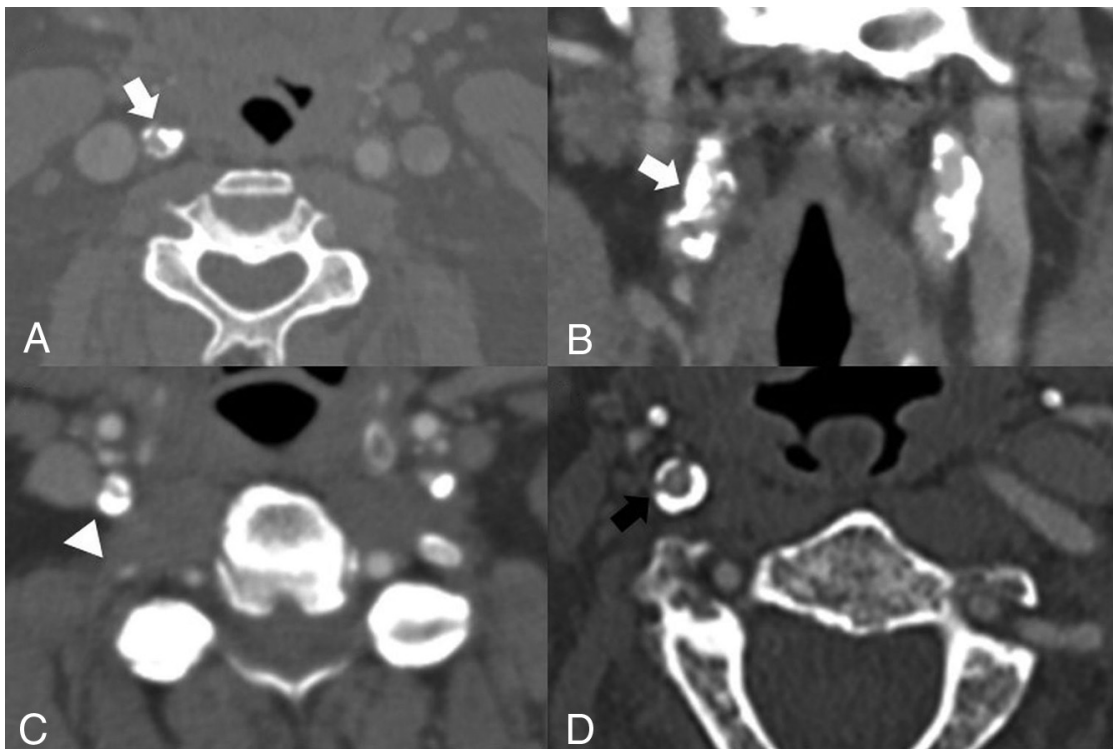

FIG 1. Examples of densely calcified plaques. $A$ and $B, A$ 73-year-old asymptomatic man with a densely calcific plaque resulting in 70\% stenosis of the proximal right ICA by the NASCET criteria (white arrows). Note the relative lack of soft or fibrofatty plaque. C, A 50-year-old man presenting with right-sided weakness found to have left MCA vascular territory infarction and with incidental note of severe (approximately $80 \%$ ) stenosis of the proximal right ICA secondary to a densely calcified plaque (arrowhead). Note the presence of a calcified plaque in the left ICA. Additional plaque was noted more proximally in the left ICA (not shown). D, An asymptomatic 81-year-old man found to have circumferential densely calcified plaque around his proximal right ICA (black arrow), with approximately $40 \%$ stenosis by the NASCET criteria.

clinical trials and for many stroke classification schemes. ${ }^{9-15}$ Recently, our understanding of the contributions of plaque features to cerebrovascular ischemia has altered how we evaluate carotid plaque. Infarctions secondary to carotid disease are thought to be caused by not only the flow-reduction from stenotic plaque but also artery-to-artery emboli occurring after fibrous cap rupture. ${ }^{16}$ We have learned that the degree of luminal stenosis does not necessarily correlate with the volume of plaque, ${ }^{17-19}$ that many plaque features besides luminal stenosis can directly contribute to ischemia, and that these high-risk features can lead to ischemic symptoms regardless of the degree of stenosis..$^{20-23}$ The disconnect between stenosis severity and stroke risk is an area of active investigation, especially in plaques causing $<50 \%$ stenosis, which are increasingly being considered as a potential cause of embolic strokes that are otherwise of uncertain etiology. ${ }^{24-26}$

Because of these recent gains in understanding, our attention is being turned to the carotid plaque itself rather than the lumen alone. The American Heart Association has rigorously defined carotid plaque on histopathology, ranging from type I, the most stable, up to type VI, the most vulnerable. ${ }^{27}$ When performing any type of plaque imaging, we seek to identify imaging correlates to these plaque features. Although 3T MR imaging is often favored when evaluating high-risk carotid plaque, many easily identifiable plaque features can be depicted on CTA and have been histopathologically validated as markers of high-risk plaque. ${ }^{28-32}$

\section{Technique}

CTA is one of the most commonly acquired imaging examinations to accurately evaluate the degree of luminal narrowing. It has a very high sensitivity (98\%), positive predictive value (93\%), and interoperator reliability in evaluating vessel patency and luminal narrowing compared with DSA. ${ }^{33}$ One benefit of using CTA for plaque evaluation is the relative standardization of the imaging technique across platforms and institutions.

There are 2 main CT techniques for evaluating plaque characteristics: the more commonly encountered MDCTA and the newer dual-source CT. CTAs are generally acquired after the intravenous administration of nonionic iodinated contrast through a peripheral IV using a power injector with a $4-\mathrm{mL} / \mathrm{s}$ flow rate and often using bolus-tracking software. Helical mode CT scanning is then generally performed with a multidetector scanner (at least 16-detector row but ideally $\geq 64$-detector row) from the aortic arch to the $\mathrm{C} 1$ ring with submillimeter (frequently $0.625-\mathrm{mm}$ ) resolution. Multiplanar reconstructions in all planes are performed to fully evaluate the vessels and to properly account for inherent vessel tortuosity. MDCTA of the carotid arteries can be rapidly acquired and is frequently used when screening patients presenting with cerebrovascular ischemic symptoms in the acute setting. For the plaque features described in this article, no postprocessing is necessary, allowing relatively rapid interpretation. Despite these clear benefits, the 2 main limitations for CTA are radiation exposure and the need to inject intravenous iodinated contrast. Another drawback to traditional MDCTA is the difficultly in differentiating calcified plaque from luminal contrast material due to their similar attenuation values. Additional considerations are that compared with ultrasound, CTA examinations are less cost-effective and are limited in the evaluation of vessel hemodynamics.

Dual-source CT can also be used when evaluating carotid plaque on CTA. Dual-source CT uses 2 different sources of $x$-rays at different kilovolts. By means of postprocessing software taking $<10$ minutes, features of specific densities such as calcified plaque or bone can be accurately segmented or subtracted to allow differentiation between the luminal iodinated contrast and adjacent calcified plaque. While this method has been increasingly studied, ${ }^{34}$ it is not as commonly available and used in acute settings.

\section{Relatively Lower Risk Features}

Plaque Calcification. The most commonly encountered lower risk feature of plaque is calcification. Plaque calcification is defined as a plaque with a Hounsfield unit $>\sim 130$ (Fig 1 and Table). Plaque calcification is most often detected visually on CTA by increasing the window width, though discriminating between calcified plaque and luminal contrast can sometimes be difficult. Calcified plaques, when detected on sonography, have 


\begin{tabular}{llc}
\hline \multicolumn{1}{c}{ Plaque Characteristic } & Imaging Definition & Histopathologic Correlate \\
\hline $\begin{array}{l}\text { Calcified plaque } \\
\text { Soft plaque }\end{array}$ & $\begin{array}{c}\text { Plaque with increased attenuation of }>130 \mathrm{HU} \\
\text { Low-attenuation plaque, around } 40-50 \mathrm{HU}\end{array}$ & $\begin{array}{c}\text { Plaque calcification } \\
\text { Intraplaque hemorrhage and lipid-rich } \\
\text { necrotic core } \\
\text { Plaque ulceration }\end{array}$ \\
$\begin{array}{l}\text { Extension of contrast material beyond the vascular } \\
\text { lumen of the plaque, usually of at least } 1 \mathrm{~mm}\end{array}$ & $\begin{array}{c}\text { Plaque surface irregularity and } \\
\text { ulceration }\end{array}$ \\
$\begin{array}{l}\text { Total plaque thickness } \\
\text { Carotid plaque enhancement }\end{array}$ & $\begin{array}{l}\text { Linear measurement of greatest axial dimension of plaque } \\
\text { Enhancement of plaque after administration of contrast }\end{array}$ & $\begin{array}{c}\text { Plaque thickness } \\
\text { Plaque neovascularity }\end{array}$ \\
\hline
\end{tabular}

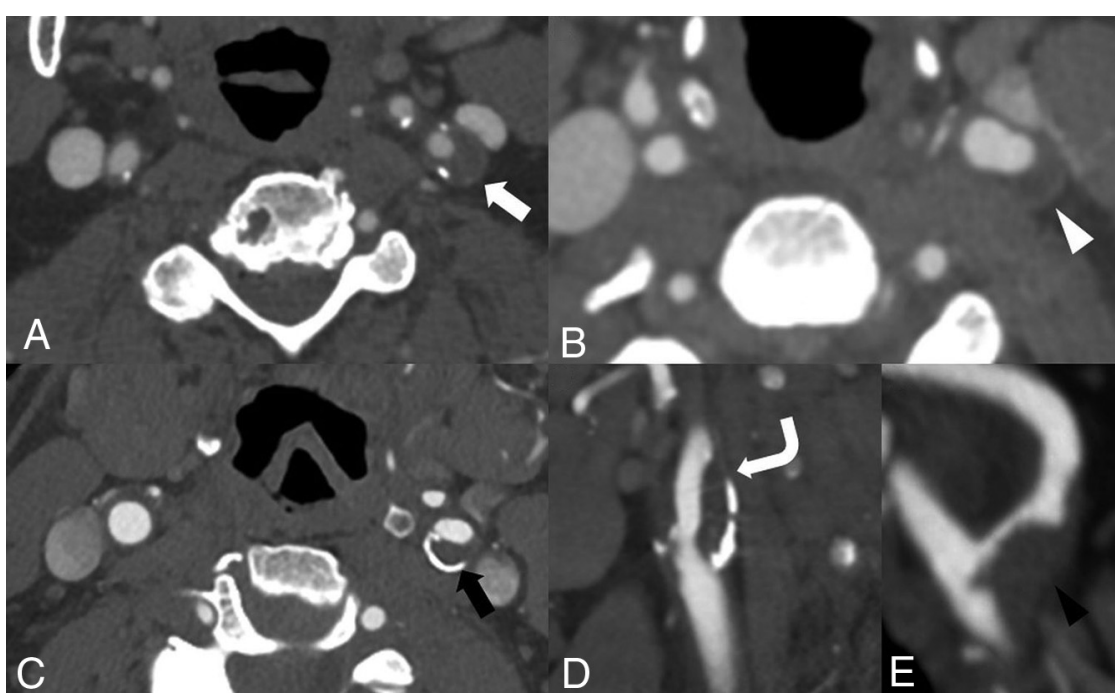

FIG 2. Soft plaque. A, 68-year-old man with a left-sided visual deficit found to have a large predominantly soft plaque (white arrow) in the proximal left ICA without significant stenosis by the NASCET criteria. B, A 74-year-old woman with right-sided weakness with a predominantly soft plaque (white arrowhead) at the left carotid bifurcation and proximal left ICA, again without significant stenosis by the NASCET criteria. C, An 82-year-old man with a large soft plaque with peripheral calcifications (black arrow) in the proximal left ICA with $<50 \%$ stenosis by the NASCET criteria. D, Sagittal reconstruction of the same patient as in $C$ demonstrates a large soft plaque component (curved arrow) extending throughout the proximal left ICA. E, Sagittal reconstruction demonstrates a large, irregular soft plaque narrowing the proximal right ICA (black arrowhead) of a 71-year-old man.

the likelihood of emboli originating from the plaque. $^{39}$ Most interesting, one study found that patients on statins were more likely to develop calcified plaques than those not on statins. ${ }^{40}$ Although we frequently encounter densely calcified plaques, which may cause a significant degree of luminal narrowing, the presence and degree of calcification may confer relatively less risk than noncalcified plaque.

\section{Relatively Higher Risk Features}

Soft Plaque. The most common highrisk feature of plaque is the so-called "soft" or "fibrofatty" plaque, which reflects a combination of intraplaque hemorrhage (IPH), lipid-rich necrotic core (LRNC), and fibrous elements. IPH and LRNC are 2 plaque features strongly associated with plaque vulnerability and an increased risk of stroke. $^{35,41-43}$ Soft plaque is plaque with a low attenuation, with a median attenuation of around 40-50 HU but ranging around 16-90 $\mathrm{HU}$ (Fig 2 and Table). Soft plaque can be seen

been found to be less frequently associated with ischemic events than noncalcified plaques. ${ }^{35}$ A systematic review and meta-analysis of 7 studies found a negative association between the presence of calcified plaque on CTA and downstream cerebrovascular ischemic symptoms, ${ }^{36}$ indicating that calcified plaques are less frequently associated with cerebrovascular ischemia. An additional systematic review also found that symptomatic plaques had less calcification than asymptomatic carotid plaques. ${ }^{37}$ Additionally, some studies have found that the ratio or thickness of calcified plaque is important. One study has shown that if $>45 \%$ of the plaque is calcified, the patient is more likely to be asymptomatic. ${ }^{38}$ Furthermore, other studies have shown that each 1-mm increase in calcified plaque decreased the odds of having had a prior ipsilateral stroke or TIA and that those with densely calcified plaques were less likely to have symptomatic disease. ${ }^{20,21}$

The lack of association between densely calcified plaque and ipsilateral stroke risk is not fully understood. Calcified plaques may decrease the fibrous cap inflammation and, in doing so, provide additional mechanical stability to the plaque surface. These features may prevent thrombus aggregation, thereby decreasing alone or in association with calcified plaque. When soft plaque is present on the luminal border with surrounding, peripheral calcification, it is thought to be a marker of high risk and is strongly associated with IPH on MR imaging. ${ }^{44}$ It can be difficult to differentiate IPH and LRNC when evaluating plaque visually on CTA, but IPH is thought to have lower Hounsfield units $^{32,45,46}$ than LRNC and fibrous elements with a mean Hounsfield units of 18 compared with LRNC (mean, $63 \mathrm{HU}$ ) and fibrous tissue (mean, $93 \mathrm{HU}$ ). ${ }^{47}$ In clinical practice, these small differences in Hounsfield units are challenging to detect accurately. Soft plaque, whether it represents IPH or LRNC, is itself a high-risk feature of plaque, so accurate discrimination between exact histologic elements in the plaque may not be essential in acknowledging the increased risk. There is high interobserver agreement in identifying large plaque hemorrhage or areas of low-density lipid cores on CTA. ${ }^{29,46}$ A systematic review and meta-analysis of 6 studies with $>1800$ arteries found that having soft plaque increases the risk of ipsilateral cerebrovascular ischemia by almost 3 times, regardless of the degree of carotid stenosis. ${ }^{36}$ As opposed to calcified 


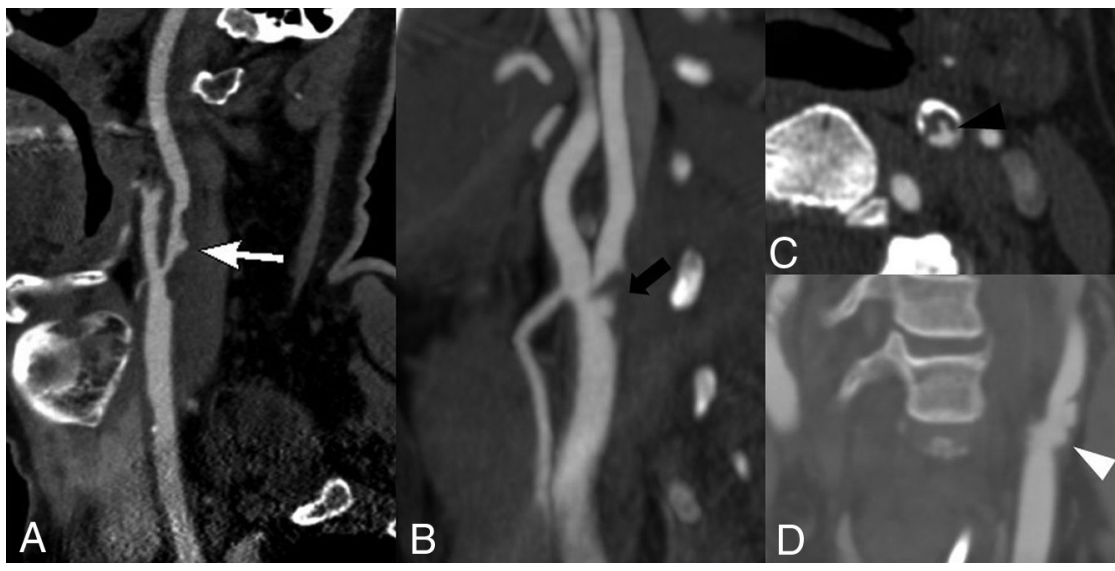

FIG 3. Plaque surface morphology and ulceration. A, A 69-year-old woman with a large soft plaque with an irregular surface and focal plaque ulceration (white arrow) with the plaque narrowing the proximal left ICA. B, A 62-year-old man with focal soft plaque at the right carotid bifurcation and proximal ICA with a large plaque ulceration (black arrow). C, A 73-year-old man with a predominant soft plaque with peripheral calcification narrowing the left ICA with focal plaque ulceration (black arrowhead) extending into the soft plaque. D, A 67-year-old woman with irregular, ulcerated plaque (white arrowhead) best seen on the coronal reconstruction. There is no significant associated luminal narrowing with this irregular, ulcerated plaque.

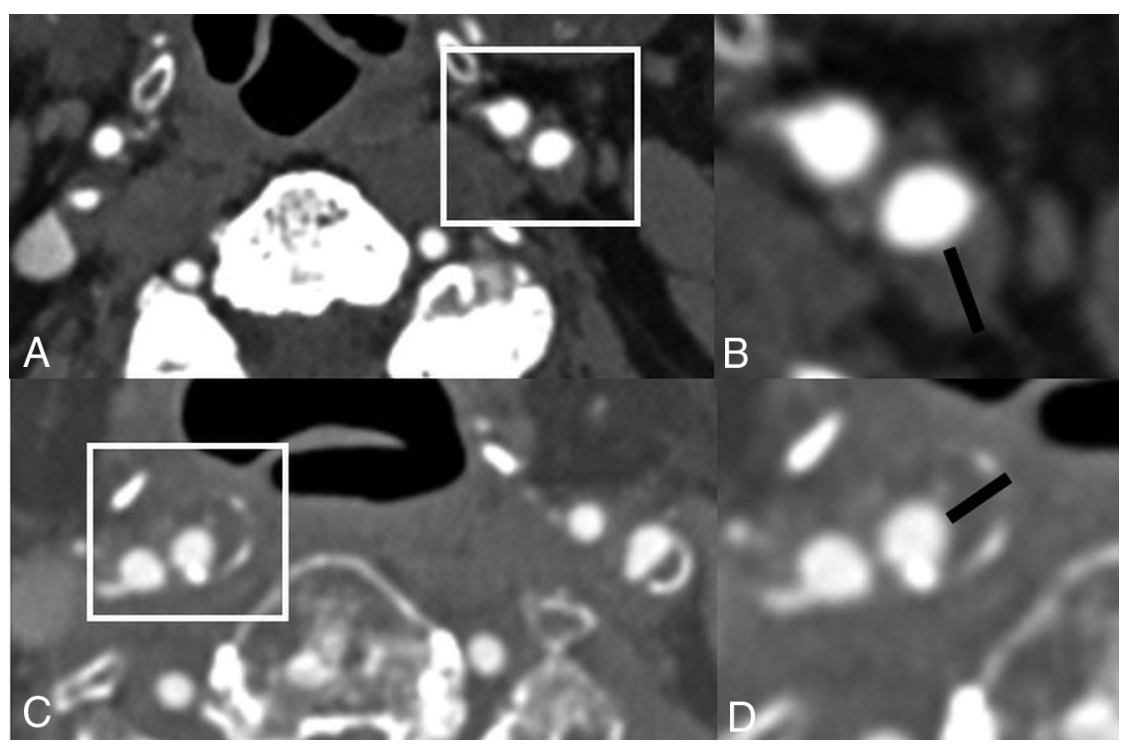

FIG 4. Plaque thickness measurements. $A$ and $B, A$ 78-year-old man with predominantly soft plaque without significant narrowing of the proximal left ICA, however, with a large soft plaque component measuring up to $5 \mathrm{~mm}$ in thickness. Despite the lack of significant narrowing, the thickness of the plaque increases the risk of ipsilateral cerebrovascular ischemia. $C$ and $D$, An 84year-old man with a large predominantly soft plaque with peripheral calcifications without signifcant stenosis by the NASCET criteria but with total plaque thickness of $4 \mathrm{~mm}$, again increasing the risk despite the lack of significant stenosis.

plaque, having an increased soft plaque thickness or an increased ratio of soft plaque increases the risk of ipsilateral cerebrovascular ischemia. $^{20,21,28}$

Overall Plaque Thickness. Beyond individual plaque components, the overall thickness of carotid artery plaque, which is easily quantifiable on CTA, is associated with plaque vulnerability. A simple linear measurement of the greatest plaque thickness can be a strong discriminator in identifying high-risk plaque (Fig 3), even better than the degree of stenosis. ${ }^{48}$ Studies have shown that greater overall plaque thickness is associated with cerebrovascular ischemic symptoms, even in patients with strokes of an undetermined source. ${ }^{48-51}$ While an exact threshold of total plaque thickness to determine increased plaque vulnerability has not been established, it may be in the 2.5to $3-\mathrm{mm}$ thickness range. ${ }^{48-50}$ This association between increasing plaque thickness and increased cerebrovascular ischemia remains, regardless of the degree of luminal narrowing.

Plaque Surface Morphology. Plaque surface irregularity is an important high-risk feature to identify because plaque rupture leading to thromboembolism is considered a critical step in the development of thromboembolic stroke. ${ }^{16,52}$ Plaque ulceration on any imaging technique is strongly associated with ischemic strokes, with hazard ratios ranging from 1.2 to $7.7 .^{53-58}$ CTA can accurately differentiate smooth, irregular, and ulcerated surfaces and can detect ulceration with high accuracy (specificity, 99\%; sensitivity, 94\%). ${ }^{59}$ Plaque ulceration on CT is described somewhat variably across studies but, in general, involves extension of contrast material beyond the vascular lumen of the plaque, usually of at least $1 \mathrm{~mm}$. Sagittal and coronal reformations can be very helpful in assessing plaque ulceration (Fig 4). A systematic review and meta-analysis of 2883 arteries found that the presence of plaque ulceration increased the likelihood of ipsilateral cerebrovascular ischemia 2.2 times. ${ }^{36}$ One of the limitations in evaluating plaque ulceration is the similarity of the attenuation of calcified plaque and luminal contrast material, which can make the detection of ulceration difficult.

Plaque ulceration is thought to increase the risk of ischemia because the ulceration exposes the inner plaque components to the flowing blood within the vessel, increasing the probability of thromboembolic events. In addition to being a high-risk feature, plaque ulceration is also associated with an increased degree of stenosis, ${ }^{60}$ increased lipid and overall plaque volume, ${ }^{61}$ and decreased volume of plaque calcifications. ${ }^{62}$ 


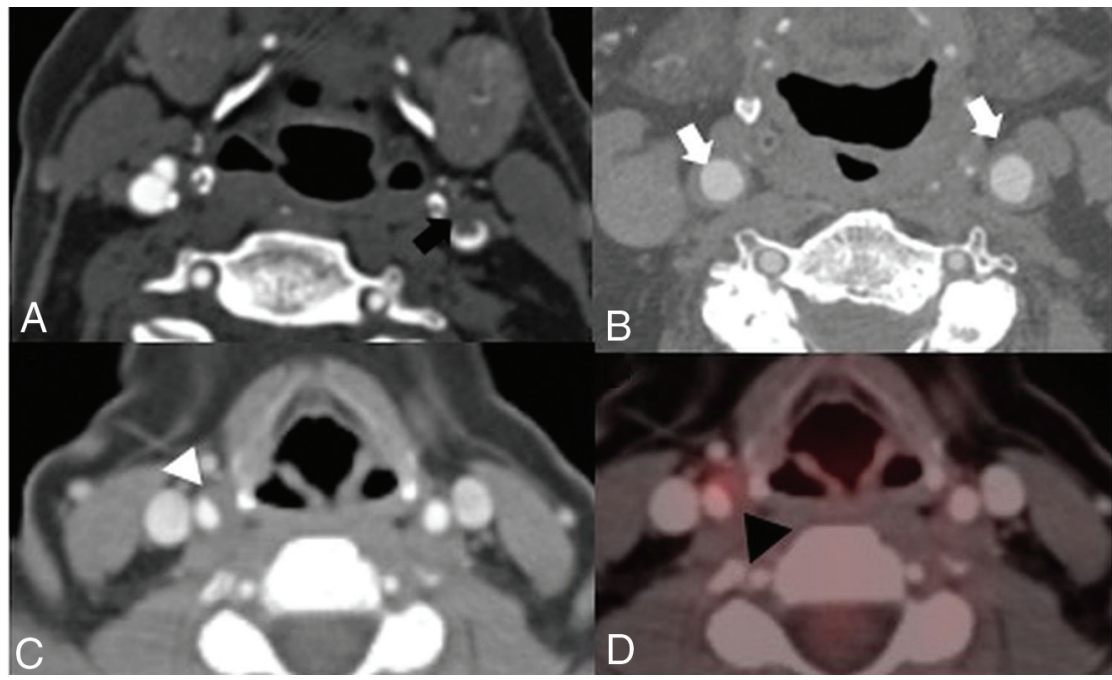

FIG 5. Plaque inflammation. $A$, An 81-year-old man presenting with left MCA territory infarction with a large soft plaque (black arrow) in the distal left common carotid artery with associated intraluminal thrombus. B, A 67-year-old man with diffuse inflammatory thickening of the distal common carotid artery walls (white arrows). $C$ and D, A 54-year-old woman with mucinous cystadenoma who had a contrast-enhanced PET/CT demonstrating a large eccentric soft plaque in the distal right common carotid artery (white arrowhead) with associated increased FDG avidity with a maximum standard uptake value of 6.3 (black arrowhead).

Neovascularization and Inflammation. Another feature indicating plaque vulnerability is inflammation and intraplaque neovascularization (Fig 5). Histopathologic studies have found an association between macrophage infiltration, plaque rupture, and ischemic symptoms ${ }^{63}$ and have confirmed that inflammatory cells accumulate with plaques. ${ }^{64}$ Additionally, studies have shown that neovessels can be seen in carotid plaques, are associated with the degree of inflammation, and increase the risk of IPH. ${ }^{65,66}$ Translating this histopathologic understanding into detectable findings on routine CTA is not as straightforward. One of the imaging correlates to plaque neovascularity and inflammation is carotid plaque enhancement, which has been shown to be associated histologically with neovascularization on $\mathrm{CTA}^{67}$ and MR imaging. ${ }^{68}$ Adventitial vasa vasorum and intraplaque neovascularization are known high-risk markers for carotid plaque inflammation and can be detected on contrastenhanced ultrasound. ${ }^{3-5}$ Additionally, arterial wall enhancement has been shown to be associated with symptomaticity. ${ }^{69,70}$ The difficulty in evaluating this feature routinely on CTA is that obtaining both pre- and postcontrast imaging of the carotid artery on CT is rarely performed in standard clinical practice. Other studies have shown that increased attenuation in the perivascular fat around the carotid arteries, indicative of surrounding inflammation, is associated with cerebrovascular ischemic symptoms. $^{71}$ In general, plaque inflammation is likely best detected using other imaging modalities, including molecular imaging studies ${ }^{72}$ and contrast-enhanced ultrasound, ${ }^{3-5}$ with a more limited role for routine CTA.

\section{Future Directions}

While there is strong evidence that the presence of specific plaque characteristics on routine CTA imaging is associated with increased recent cerebrovascular ischemic symptoms, including in patients with strokes, that would otherwise be classified as "cryptogenic," there are limited prospective data using CTA in asymptomatic individuals who are then followed across time to a firsttime cerebrovascular ischemic event. Many prospective studies on histopathologically verified high-risk features on MR imaging and ultrasound plaque have been performed or are being performed $^{73-75}$ and have shown an increased risk of future or recurrent cerebrovascular ischemia, but similar prospective studies have not been performed using CTA as the primary imaging technique. Prospective studies with standardized protocols and plaque characteristic definitions to determine the predictive abilities of these plaque features on CTA are certainly warranted. Future studies should also more fully evaluate the role of CTA in monitoring the response of plaque characteristics to medical therapy, especially in light of various novel treatments that allow significant intensification of medical therapy as a potential alternative to revascularization procedures.

\section{CONCLUSIONS}

Routine CTA can provide a detailed assessment of plaque vulnerability, beyond the standard degree of luminal stenosis. Many plaque features can be assessed on routinely acquired CTA examinations without additional postprocessing or excessive delay in interpretation. There is strong evidence showing an association with the described plaque features and cerebrovascular ischemic symptoms. Accurate recognition of these plaque features may assist in appropriate risk stratification.

Disclosures: Hediyeh Baradaran-RELATED: Grant: Association of University Radiologists-GE Radiology Research Academic Fellowship. Money paid to the institution.

\section{REFERENCES}

1. Saba L, Yuan C, Hatsukami TS, et al; Vessel Wall Imaging Study Group of the American Society of Neuroradiology. Carotid artery wall imaging: perspective and guidelines from the ASNR Vessel Wall Imaging Study Group and Expert Consensus Recommendations of the American Society of Neuroradiology. AJNR Am J Neuroradiol 2018;39:E9-31 CrossRef Medline

2. Brinjikji W, Huston J, Rabinstein AA, et al. Contemporary carotid imaging: from degree of stenosis to plaque vulnerability. $J$ Neurosurg 2016;124:27-42 CrossRef Medline

3. Staub D, Partovi S, Schinkel AF, et al. Correlation of carotid artery atherosclerotic lesion echogenicity and severity at standard US with intraplaque neovascularization detected at contrast-enhanced US. Radiology 2011;258:618-26 CrossRef Medline 
4. Staub D, Partovi S, Imfeld S, et al. Novel applications of contrastenhanced ultrasound imaging in vascular medicine. Vasa 2013; 42:17-31 CrossRef Medline

5. Partovi S, Loebe M, Aschwanden M, et al. Contrast-enhanced ultrasound for assessing carotid atherosclerotic plaque lesions. AJR Am J Roentgenol 2012;198:W13-19 CrossRef Medline

6. Sacco RL, Kargman DE, Gu Q, et al. Race-ethnicity and determinants of intracranial atherosclerotic cerebral infarction. Stroke 1995;26:14-20 CrossRef Medline

7. Wityk RJ, Lehman D, Klag M, et al. Race and sex differences in the distribution of cerebral atherosclerosis. Stroke 1996;27:1974-80 CrossRef Medline

8. Raman G, Moorthy D, Hadar N, et al. Management strategies for asymptomatic carotid stenosis: a systematic review and meta-analysis. Ann Intern Med 2013;158:676-85 CrossRef Medline

9. Adams HP, Bendixen BH, Kappelle LJ, et al. Classification of subtype of acute ischemic stroke: definitions for use in a multicenter clinical trial-Toast. Trial of Org 10172 in Acute Stroke Treatment. Stroke 1993;24:35-41 CrossRef Medline

10. Barnett $H$, Taylor D, Eliasziw $M$, et al. Benefit of carotid endarterectomy in patients with symptomatic moderate or severe stenosis. $\mathrm{N}$ Engl J Med 1998;339:1415-25 CrossRef Medline

11. Randomised trial of endarterectomy for recently symptomatic carotid stenosis: final results of the MRC European Carotid Surgery Trial (ECST). Lancet 1998;351:1379-87 Medline

12. Halliday A, Mansfield A, Marro J, et al; MRC Asymptomatic Carotid Surgery Trial (ACST) Collaborative Group. Prevention of disabling and fatal strokes by successful carotid endarterectomy in patients without recent neurological symptoms: randomised controlled trial. Lancet 2004;363:1491-1502 CrossRef Medline

13. Hobson R, Weiss D, Fields W, et al. Efficacy of carotid endarterectomy for asymptomatic carotid stenosis. $N$ Engl J Med 1993;328: 221-27 CrossRef Medline

14. Walker LJ, Ismail A, McMeekin W, et al. Computed tomography angiography for the evaluation of carotid atherosclerotic plaque: correlation with histopathology of endarterectomy specimens. Stroke 2002;33:977-81 CrossRef Medline

15. Barnett HJ, Taylor DW, Haynes RB, et al; North American Symptomatic Carotid Endarterectomy Trial Collaborators. Beneficial effect of carotid endarterectomy in symptomatic patients with high-grade carotid stenosis. $N$ Engl J Med 1991;325:445-53 CrossRef Medline

16. Caplan LR, Hennerici M. Impaired clearance of emboli (washout) is an important link between hypoperfusion, embolism, and ischemic stroke. Arch Neurol 1998;55:1475-82 CrossRef Medline

17. Mono ML, Karameshev A, Slotboom J, et al. Plaque characteristics of asymptomatic carotid stenosis and risk of stroke. Cerebrovasc Dis 2012;34:343-50 CrossRef Medline

18. Rozie S, De Weert T, De Monyé C, et al. Atherosclerotic plaque volume and composition in symptomatic carotid arteries assessed with multidetector CT angiography; relationship with severity of stenosis and cardiovascular risk factors. Eur Radiol 2009;19:2294301 CrossRef Medline

19. Saam T, Yuan C, Chu B, et al. Predictors of carotid atherosclerotic plaque progression as measured by noninvasive magnetic resonance imaging. Atherosclerosis 2007;194:e34-42 CrossRef Medline

20. Gupta A, Baradaran H, Kamel H, et al. Evaluation of computed tomography angiography plaque thickness measurements in high-grade carotid artery stenosis. Stroke 2014;45:740-45 CrossRef Medline

21. Gupta A, Mtui EE, Baradaran $\mathrm{H}$, et al. CT angiographic features of symptom-producing plaque in moderate-grade carotid artery stenosis. AJNR Am J Neuroradiol 2015;36:349-54 CrossRef Medline

22. Saba L, Montisci R, Sanfilippo R, et al. Multidetector row CT of the brain and carotid artery: a correlative analysis. Clin Radiol 2009; 64:767-78 CrossRef Medline

23. Ota $\mathrm{H}, \mathrm{Yu} \mathrm{W}$, Underhill $\mathrm{HR}$, et al. Hemorrhage and large lipid-rich necrotic cores are independently associated with thin or ruptured fibrous caps: an in vivo 3T MRI study. Arterioscler Thromb Vasc Biol 2009;29:1696-701 CrossRef Medline

24. Gupta A, Gialdini G, Lerario MP, et al. Magnetic resonance angiography detection of abnormal carotid artery plaque in patients with cryptogenic stroke. J Am Heart Assoc 2015;4:e002012 CrossRef Medline

25. Gupta A, Gialdini G, Giambrone AE, et al. Association between nonstenosing carotid artery plaque on MR angiography and acute ischemic stroke. JACC Cardiovasc Imaging 2016;9:1228-29 CrossRef Medline

26. Kamel H, Merkler AE, Iadecola C, et al. Tailoring the approach to embolic stroke of undetermined source: a review. JAMA Neurol 2019;76:855-61 CrossRef Medline

27. Stary HC, Chandler AB, Dinsmore RE, et al. A definition of advanced types of atherosclerotic lesions and a histological classification of atherosclerosis: a report from the Committee on Vascular Lesions of the Council on Arteriosclerosis, American Heart Association. Circulation 1995;92:1355-74 CrossRef Medline

28. Trelles M, Eberhardt K, Buchholz M, et al. CTA for screening of complicated atherosclerotic carotid plaque: American Heart Association type VI lesions as defined by MRI. AJNR Am J Neuroradiol 2013;34:2331-37 CrossRef Medline

29. Wintermark M, Jawadi SS, Rapp JH, et al. High-resolution CT imaging of carotid artery atherosclerotic plaques. AJNR Am J Neuroradiol 2008;29:875-82 CrossRef Medline

30. Gupta A, Baradaran H, Mtui EE, et al. Detection of symptomatic carotid plaque using source data from MR and CT angiography: a correlative study. Cerebrovasc Dis 2015;39:151-61 CrossRef Medline

31. Oliver TB, Lammie GA, Wright AR, et al. Atherosclerotic plaque at the carotid bifurcation: $C T$ angiographic appearance with histopathologic correlation. AJNR Am J Neuroradiol 1999;20:897-901 Medline

32. de Weert TT, Ouhlous M, Meijering E, et al. In vivo characterization and quantification of atherosclerotic carotid plaque components with multidetector computed tomography and histopathological correlation. Arterioscler Thromb Vasc Biol 2006;26:2366-72 CrossRef Medline

33. Bash S, Villablanca JP, Jahan R, et al. Intracranial vascular stenosis and occlusive disease: evaluation with $\mathrm{CT}$ angiography, MR angiography, and digital subtraction angiography. AJNR Am J Neuroradiol 2005;26:1012-21 CrossRef Medline

34. Das M, Braunschweig T, Mühlenbruch G, et al. Carotid plaque analysis: comparison of dual-source computed tomography (CT) findings and histopathological correlation. Eur J Vasc Endovasc Surg 2009;38:14-19 CrossRef Medline

35. Gupta A, Kesavabhotla K, Baradaran H, et al. Plaque echolucency and stroke risk in asymptomatic carotid stenosis: a systematic review and meta-analysis. Stroke 2015;46:91-97 CrossRef Medline

36. Baradaran H, Al-Dasuqi K, Knight-Greenfield A, et al. Association between carotid plaque features on CTA and cerebrovascular ischemia: a systematic review and meta-analysis. AJNR Am J Neuroradiol 2017;38:2321-26 CrossRef

37. Kwee R. Systematic review on the association between calcification in carotid plaques and clinical ischemic symptoms. J Vasc Surg 2010;51:1015-25 CrossRef Medline

38. Nandalur KR, Hardie AD, Raghavan P, et al. Composition of the stable carotid plaque. Stroke 2007;38:935-40 CrossRef Medline

39. Shaalan WE, Cheng H, Gewertz B, et al. Degree of carotid plaque calcification in relation to symptomatic outcome and plaque inflammation. J Vasc Surg 2004;40:262-69 CrossRef Medline

40. Adraktas DD, Tong E, Furtado AD, et al. Evolution of CT imaging features of carotid atherosclerotic plaques in a 1-year prospective cohort study. J Neuroimaging 2014;24:1-6 CrossRef Medline

41. Gupta A, Baradaran H, Schweitzer AD, et al. Carotid plaque MRI and stroke risk. Stroke 2013;44:3071-77 CrossRef Medline

42. Golemati S, Tegos TJ, Sassano A, et al. Echogenicity of b-mode sonographic images of the carotid artery: work in progress. $J$ Ultrasound Med 2004;23:659-69 CrossRef Medline 
43. Saam T, Hetterich H, Hoffmann V, et al. Meta-analysis and systematic review of the predictive value of carotid plaque hemorrhage on cerebrovascular events by magnetic resonance imaging. $\mathrm{J} \mathrm{Am}$ Coll Cardiol 2013;62:1081-91 CrossRef Medline

44. Eisenmenger LB, Aldred BW, Kim SE, et al. Prediction of carotid intraplaque hemorrhage using adventitial calcification and plaque thickness on CTA. AJNR Am J Neuroradiol 2016;37:1496-1503 CrossRef Medline

45. Ajduk M, Bulimbasic S, Pavic L, et al. Comparison of multidetectorrow computed tomography and duplex Doppler ultrasonography in detecting atherosclerotic carotid plaques complicated with intraplaque hemorrhage. Coll Antropol 2013;37:213-19 Medline

46. Ajduk M, Pavić L, Bulimbašić S, et al. Multidetector-row computed tomography in evaluation of atherosclerotic carotid plaques complicated with intraplaque hemorrhage. Ann Vasc Surg 2009;23:18693 CrossRef Medline

47. Saba L, Francone M, Bassareo PP, et al. CT attenuation analysis of carotid intraplaque hemorrhage. AJNR Am J Neuroradiol 2018;39: 131-37 CrossRef Medline

48. Zhao X, Hippe Daniel S, Li R, et al; CARE-II Study Collaborators. Prevalence and characteristics of carotid artery high-risk atherosclerotic plaques in Chinese patients with cerebrovascular symptoms: a Chinese atherosclerosis risk evaluation II study. J Am Heart Assoc 2017;6:e005831 CrossRef Medline

49. Coutinho JM, Derkatch S, Potvin ARJ, et al. Nonstenotic carotid plaque on CT angiography in patients with cryptogenic stroke. Neurology 2016;87:665-72 CrossRef Medline

50. McLaughlin MS, Hinckley PJ, Treiman SM, et al. Optimal prediction of carotid intraplaque hemorrhage using clinical and lumen imaging markers. AJNR Am J Neuroradiol 2015;36:2360-66 CrossRef Medline

51. Magge R, Lau BC, Soares BP, et al. Clinical risk factors and CT imaging features of carotid atherosclerotic plaques as predictors of new incident carotid ischemic stroke: a retrospective cohort study. AJNR Am J Neuroradiol 2013;34:402-09 CrossRef Medline

52. Virmani R, Ladich ER, Burke AP, et al. Histopathology of carotid atherosclerotic disease. Neurosurgery 2006;59:S213-27 CrossRef

53. Eliasziw M, Streifler JY, Fox AJ, et al. Significance of plaque ulceration in symptomatic patients with high-grade carotid stenosis: North American Symptomatic Carotid Endarterectomy trial. Stroke 1994;25:304-08 CrossRef Medline

54. Handa N, Matsumoto M, Maeda $H$, et al. Ischemic stroke events and carotid atherosclerosis. Stroke 1995;26:1781-86 CrossRef Medline

55. Rothwell PM, Gibson R, Warlow CP. Interrelation between plaque surface morphology and degree of stenosis on carotid angiograms and the risk of ischemic stroke in patients with symptomatic carotid stenosis. Stroke 2000;31:615-21 CrossRef Medline

56. Rothwell PM, Mehta Z, Howard SC, et al. From subgroups to individuals: general principles and the example of carotid endarterectomy. Lancet 2005;365:256-65 CrossRef Medline

57. Prabhakaran S, Rundek T, Ramas R, et al. Carotid plaque surface irregularity predicts ischemic stroke. Stroke 2006;37:2696-701 CrossRef Medline

58. Kuk M, Wannarong T, Beletsky V, et al. Volume of carotid artery ulceration as a predictor of cardiovascular events. Stroke 2014;45: 1437-41 CrossRef Medline

59. Saba L, Caddeo G, Sanfilippo R, et al. Efficacy and sensitivity of axial scans and different reconstruction methods in the study of the ulcerated carotid plaque using multidetector-row CT angiography: comparison with surgical results. AJNR Am J Neuroradiol 2007;28: 716-23 CrossRef Medline

60. Saba L, Caddeo G, Sanfilippo R, et al. CT and ultrasound in the study of ulcerated carotid plaque compared with surgical results: potentialities and advantages of multidetector row CT angiography. AJNR Am J Neuroradiol 2007;28:1061-66 CrossRef Medline

61. Saba L, Sanfilippo R, Sannia S, et al. Association between carotid artery plaque volume, composition, and ulceration: a retrospective assessment with MDCT. AJR Am J Roentgenol 2012;199:151-56 CrossRef Medline

62. Homburg PJ, Rozie S, van Gils MJ, et al. Association between carotid artery plaque ulceration and plaque composition evaluated with multidetector CT angiography. Stroke 2011;42:367-72 CrossRef Medline

63. Yuan XM, Ward LJ, Forssell C, et al. Carotid atheroma from men has significantly higher levels of inflammation and iron metabolism enabled by macrophages. Stroke 2018;49:419-25 CrossRef Medline

64. Moulton KS, Vakili K, Zurakowski D, et al. Inhibition of plaque neovascularization reduces macrophage accumulation and progression of advanced atherosclerosis. Proc Natl Acad Sci USA 2003; 100:4736-41 CrossRef Medline

65. Virmani R, Kolodgie FD, Burke AP, et al. Atherosclerotic plaque progression and vulnerability to rupture. Arterioscler Thromb Vasc Biol 2005;25:2054-61 CrossRef Medline

66. McCarthy MJ, Loftus IM, Thompson MM, et al. Angiogenesis and the atherosclerotic carotid plaque: an association between symptomatology and plaque morphology. J Vasc Surg 1999;30:261-68 CrossRef Medline

67. Saba L, Lai ML, Montisci R, et al. Association between carotid plaque enhancement shown by multidetector CT angiography and histologically validated microvessel density. Eur Radiol 2012;22: 2237-45 CrossRef Medline

68. Qiao Y, Etesami M, Astor BC, et al. Carotid plaque neovascularization and hemorrhage detected by MR imaging are associated with recent cerebrovascular ischemic events. AJNR Am J Neuroradiol 2012;33:755-60 CrossRef Medline

69. Romero JM, Babiarz LS, Forero NP, et al. Arterial wall enhancement overlying carotid plaque on CT angiography correlates with symptoms in patients with high grade stenosis. Stroke 2009;40:1894-96 CrossRef Medline

70. Romero JM, Pizzolato R, Atkinson W, et al. Vasa vasorum enhancement on computerized tomographic angiography correlates with symptomatic patients with $50 \%$ to $\mathbf{7 0} \%$ carotid artery stenosis. Stroke 2013;44:3344-49 CrossRef Medline

71. Baradaran H, Myneni PK, Patel P, et al. Association between carotid artery perivascular fat density and cerebrovascular ischemic events. J Am Heart Assoc 2018;7:e010383 CrossRef Medline

72. Chaker S, Al-Dasuqi K, Baradaran $\mathrm{H}$, et al. Carotid plaque positron emission tomography imaging and cerebral ischemic disease: a systematic review and meta-analysis. Stroke 2019;50:2072-79 CrossRef Medline

73. Zhao XQ, Hatsukami TS, Hippe DS, et al; AIM-HIGH Carotid MRI Sub-Study Investigators. Clinical factors associated with high-risk carotid plaque features as assessed by magnetic resonance imaging in patients with established vascular disease (from the AIM-HIGH study). Am J Cardiol 2014;114:1412-19 CrossRef Medline

74. van Dijk AC, Truijman M, Hussain B, et al. Intraplaque hemorrhage and the plaque surface in carotid atherosclerosis: the Plaque At Risk Study (PARISK). AJNR Am J Neuroradiol 2015;36:2127-33 CrossRef Medline

75. Zavodni AE, Wasserman BA, McClelland RL, et al. Carotid artery plaque morphology and composition in relation to incident cardiovascular events: the multi-ethnic study of atherosclerosis (MESA). Radiology 2014;271:381-89 CrossRef Medline 